\title{
Fracture saturation in paintings makes them less vulnerable to environmental variations in museums
}

Łukasz Bratasz ${ }^{1,2^{*}} \mathbb{0}$, Kiraz Goze Akoglu and Patrick Kékicheff ${ }^{3}$

\begin{abstract}
Understanding paintings as physical systems is fundamental for advancing environmental specifications that would allow for effective management of museum environments in terms of reducing energy use and carbon emissions while maintaining high standards of collection care. The current environmental specifications were derived using the criterion of the crack initiation in undamaged, usually new, material. In reality, historical paintings exhibit complex crack patterns called craquelures. The present paper analyses painted wood which is among the category of cultural objects most vulnerable to relative humidity and temperature fluctuations and frequently found in museum collections of various kinds. Fracture toughness determined experimentally for the most brittle component of pictorial layer - the ground layer (gesso) is used as a 'failure criterion'. Comparison of energy release rate — calculated for the model of the gesso laid on a wooden substrate using finite element analysis - with the structure toughness, allowed the fracture saturation expressed as the ratio of spacing between cracks $S$ to gesso layer thickness $t$ to be determined for various combinations of the gesso stiffness and geometries of structural flaws at which cracks initiate. For flat geometry of a panel painting and panel thickness of $40 \mathrm{~mm}$, representing the worst-case, largest stresses in the gesso layer, the fracture saturation occurs when $S / t$ is larger than 5 , even if flaws in the gesso layer are present. The paper shows that the fracture saturation significantly changes vulnerability of paintings to climate variations - a panel painting with developed craquelure network is significantly less vulnerable to climate variations than an undamaged one.
\end{abstract}

Keywords: Paintings, Craquelures, Fracture saturation, Relative humidity, Preventive conservation, Environmental specifications, Damage, Museums

\section{Introduction}

Until it was gradually replaced by canvas in the sixteenth century, wood had served for centuries as a support for paintings in Europe. Painted wood, particularly panel paintings, is among the most precious and frequently exhibited category of heritage objects which at the same time is most vulnerable to relative humidity $(\mathrm{RH})$ and temperature fluctuations. Paintings on wood are complex multi-layer structures composed of a wood support sized with animal glue, a preparatory layer of

\footnotetext{
*Correspondence: ncbratas@cyf-kr.edu.pl

2 Jerzy Haber Institute of Catalysis and Surface Chemistry Polish Academy of Sciences, 30-239 Kraków, Poland

Full list of author information is available at the end of the article
}

gesso-a mixture of animal glue and white inert solidto produce a smooth painting surface, and paints and varnishes on the top. All materials constituting painted wood are humidity sensitive: they swell when they gain moisture and shrink when they lose it, which generates hygric stresses owing to materials' different dimensional response to the loss or gain of moisture. Wood is anisotropic and its moisture-related dimensional changes vary in its three principal anatomical axes-longitudinal, or parallel to grain, radial and tangential. The most pronounced moisture response is in the tangential direction and it halves in the radial one. The swelling and shrinkage behaviour of individual wood species in the radial and tangential directions was reported for 21 wood species used in the past for panel paintings and woodcarving [1].
Springer Open

(c) The Author(s) 2020. This article is licensed under a Creative Commons Attribution 4.0 International License, which permits use, sharing, adaptation, distribution and reproduction in any medium or format, as long as you give appropriate credit to the original author(s) and the source, provide a link to the Creative Commons licence, and indicate if changes were made. The images or other third party material in this article are included in the article's Creative Commons licence, unless indicated otherwise in a credit line to the material. If material is not included in the article's Creative Commons licence and your intended use is not permitted by statutory regulation or exceeds the permitted use, you will need to obtain permission directly from the copyright holder. To view a copy of this licence, visit http://creativeco mmons.org/licenses/by/4.0/. The Creative Commons Public Domain Dedication waiver (http://creativecommons.org/publicdomain/ zero/1.0/) applies to the data made available in this article, unless otherwise stated in a credit line to the data. 
For practical purposes, wood can be considered dimensionally stable parallel to its grain.

The mismatch in the moisture response of gesso and unrestrained wood substrate, in the direction across the grain, especially the most responsive tangential direction, has been identified as the worst-case condition for fracturing of the entire pictorial layer. The gesso layer experiences tension during wood swelling, which leads to cracking if the strain generated by a wooden support goes beyond the critical level [2]. The notion that the deterioration of objects is related to indoor climate instability, existed long before the first museums were created. Already the artisans making the supports added crossbeams or combinations of crossbeams and longitudinal struts to confer greater planarity and dimensional stability to the panels under unavoidable humidity changes. Also, the concept of stabilising RH changes in the environment of paintings was gradually reflected in good practice and housekeeping rules, which over the last century evolved into the climate specifications for museums we know today. Until the beginning of 1990s, these specifications were based on the technical capabilities of climate control systems rather than experimental or theoretical evidence of collections needs. As a result, climate control specifications were very stringent-and in many museums still are-both in temperature (typically 21 or $22 \pm 1{ }^{\circ} \mathrm{C}$ ) and $\mathrm{RH}$ (typically $50 \pm 5 \%$ ) [3]. Only since 1990s, the dimensional response of materials to climatic changes and the critical levels of strain at which the materials began to deform plastically or fracture were studied in the laboratory $[2,4,5]$, which led to the development of evidence-based environmental specifications for collections of historical objects [6, 7]. Moderate variations within the approximate RH range of $40-60 \%$ (or $\pm 10 \%$ around the long-term average $\mathrm{RH}$ of $50 \%$ ) were indicated as safe for paintings, whereas fluctuations beyond $20 \%$ $\mathrm{RH}$ caused rapidly increasing risk of fracture. The results informed a joint declaration on environmental guidelines by the International Institute for Conservation and the International Council of Museums [8] as well as practice of climate control in many museums. The evidencebased, more relaxed environmental specifications have been an indisputable progress in the rational climate control in museums also because experiences of numerous institutions have shown that even a slight relaxation of the specifications can reduce energy consumption and the use of fossil fuels significantly [9-11]. For example, the Smithsonian Institution reduced energy costs by $17 \%$ by widening the range of allowable $\mathrm{RH}$ fluctuations from \pm 5 to $\pm 8 \%$. Additionally, relaxed environmental control mitigates risk of moisture related damage to the building envelope, particularly in winter [3].
The above 'safe' $\mathrm{RH}$ range was derived using the extreme of a conservative criterion of the gesso crack initiation in undamaged, usually new, material. In reality, historical painted objects, especially panel paintings, with their long environmental history, exhibit complex crack patterns called craquelures. Cracks in paintings can be referred to as 'edge fractures' as they are initiated from the free surface. The craquelure patterns in a painting are related both to drying shrinkage of a pictorial layer, and to environmental and physical impacts which the painting experienced in its history. The terms 'drying' and 'aging' cracks were used to describe these two groups of cracks, respectively [12]. Investigations on development of cracks in freshly prepared gesso layers demonstrated that historically drying cracks developed fully and stabilized within several years after the painting was executed and exposed in a building with unavoidably uncontrolled climate [13]. Drying leads to isotropic 'mud crack patterns' as the principal stresses in directions parallel to the free surface are similar [14]. In turn, mismatch in moisture induced swelling of gesso and wood substrate leads to a set of parallel cracks (Fig. 1) as the stress distribution in the gesso is dominated by one principal stress perpendicular to the wood grain [15].

The phenomenon of fracturing in layered materials owing to desiccation, cooling and shrinkage is commonly observed in man-made and natural materials. Fractures were extensively studied in mechanical and

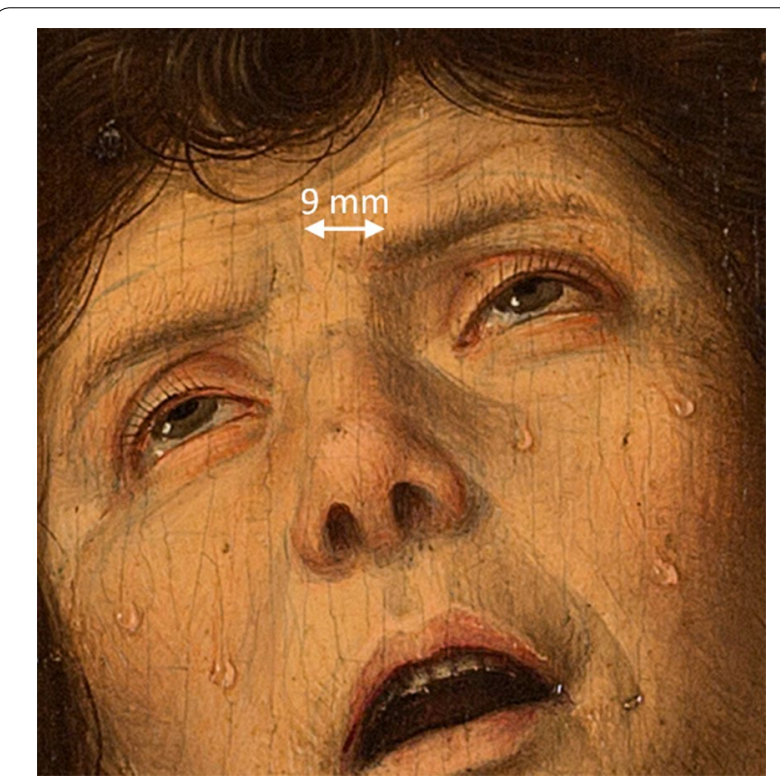

Fig. 1 Hans Memling, The Last Judgment, a detail. Distemper, oil on wood, painted c. 1467-1471, owned by the National Museum in Gdańsk, Poland. Predominantly parallel cracks were induced in the past by swelling of the wood substrate. The image is used with permision of the National Museum in Gdańsk. Photo: Piotr Frączek and Michał Obarzanowski 
civil engineering, material science, earth and geological sciences [14, 16-19]. More recently, first studies in the field of heritage science were also reported $[20,21]$. The fracture development in layered materials is due to stress transfer from the intact substrate to the fractured layer in the area between neighbouring fractures. If the substrate expands, the tension in the middle between two fractures reaches the maximal value [14]. If the strength of the material is exceeded, a new crack nucleates. When a distance between cracks becomes small, an additional tensile load does not initiate new fractures as the stress in the centre between two adjacent fractures is no longer tensile but becomes compressive, independently of the value of applied stress [22, 23]. The critical spacing in a twolayer isotropic system was demonstrated to depend on the ratio of elasticity moduli and Poisson coefficients for fractured and underlying layers, respectively. Similar dependences were shown for orthotropic wooden substrates. The critical crack spacing for radially cut panels was larger than for panels cut tangentially when compared to values obtained for the isotropic material, owing to differences in elasticity moduli and Poisson coefficients in these two anatomical directions. The critical crack spacing estimated for material properties typical of panel paintings agreed well with distances between cracks observed in selected real paintings [21]. The estimations were limited to an ideal case in which the painting remained flat during an $\mathrm{RH}$ variation and the gesso layer was free of structural defects.

The aim of the present study has been to use fracture mechanics approach to analyse the process of crack saturation in systems reflecting the physical reality of true panel paintings. First, cupping of panel paintings - that is to say their deviation from flatness across the width of a panel-was considered. Under $\mathrm{RH}$ variations, the wood support may experience uneven moisture change, and consequently uneven dimensional response, in opposite faces of a panel due to a lower permeability of the painted face to the moisture flow $[24,25]$. The stress induced by the uneven response manifests by cupping concave to the drier face which disappears as moisture content becomes uniform across the panel [26]. For thinner panels and stiff gesso, cupping is also an outcome of a restraint on wood uniform swelling exerted by the gesso layer. Both mechanisms can cause permanent deformation when the stress has gone beyond the critical level. Secondly, the effect of structural defects on the crack saturation was explored taking into account varying size and position of a defect in the gesso layer as the defects might propagate causing further infilling between cracks.

\section{Materials and methods \\ Gessoes}

Several gesso recipes were used to determine dependence of material's mechanical parameters on various compositions expressed as a ratio of the inert solid, 'the pigment', to the glue. The ratio is expressed as the pigment volume concentration in percent $\mathrm{PVC}=\mathrm{P} /(\mathrm{P}+\mathrm{B})$ where $\mathrm{P}$ and $\mathrm{B}$ are volumes of the pigment and the dried glue binder, respectively. Both the strength of the glue and the PVC affect the mechanical properties of the gesso. PVC values ranging between 85 and $95 \%$ were selected as typical recipes of usable gessoes $[27,28]$. The preparation procedure adopted after Cennino Cennini, ca. 1400 [29] is contained in Additional file 1.

\section{Determining mechanical properties of gessoes}

The ASTM D5528-13 standard of the American Society for Testing and Materials was adopted to determine interlaminar fracture energy of the gesso in the opening mode $I, G_{I C}$ [30]. During the test, double cantilever beam (DCB) specimens are split in tensile tests. The DCB specimens imitating panel paintings were designed and prepared to reflect traditional techniques used by artists in the past and currently by conservators. Two wooden boards were sized with rabbit skin glue, dried and conditioned at $25{ }^{\circ} \mathrm{C}$ and $75 \% \mathrm{RH}$. Then, a warm gesso was applied with a syringe in the centre of the sized face and the second wooden support was placed gently on the gesso island while uniform thickness of the gesso layer was ensured by spacers. Two aluminium foils were placed at the one end to create a pre-crack in a controlled way. The specimens were left under pressure, and, before the test, equilibrated at $25^{\circ} \mathrm{C}$ to the required $\mathrm{RH}$ of $30,50,75$ or $90 \%$ for 14 days. Finally, loading blocks were attached. In total, 5-10 DCB specimens were tested to calculate average $G_{I C}$ value and uncertainty-standard deviationfor various PVC and RH. Gesso stiffness was determined for the same set of gesso specimens in separate tensile tests. A diagram of a double cantilever beam specimen with the loading blocks, details of the specimen preparation and the tensile tests performed are contained in Additional file 1 together with typical examples of crack growth and load versus displacement relationships for selected gesso samples.

\section{Computerized microtomography}

Computerized microtomography data were collected on a RXSolutions EasyTom 150-160 tomograph. The $\mathrm{X}$-rays are emitted from a tungsten target (with a Hamamatsu Open Type Microfocus X-ray source operating at a $80 \mathrm{kV}$ tube voltage and $62 \mu \mathrm{A}$ tube current) and a polychromatic, divergent beam is generated with a conical solid angle of $140^{\circ}$. The sample was placed in between 
the source and the detector (distance source-detector $279 \mathrm{~mm}$ ) and moved in order to adjust the resolution to $3 \mu \mathrm{m}$ (distance sample-detector $6.6 \mathrm{~mm}$ ). The VARIAN PaxScan 2520DX detector is a fluoroscopic high resolution, real-time digital X-ray imaging device, commonly referred to as a flat panel detector, with $1920 \times 1536$ pixels on $127 \mu \mathrm{m}$ pixel pitch, 16-bit X-ray camera. Before scanning the sample, the focus was fine-adjusted for obtaining optimal X-ray images. A small parallelepiped (square section about $5 \times 5 \mathrm{~mm}^{2}$; height $25 \mathrm{~mm}$ ) woodpainted sample was fixed on the top of a vertical carbon fiber rod, which was mounted on a high-resolution rotary stage and illuminated with X-rays. Projections (radiographs) were collected at fixed angular increments $\left(0.25^{\circ}\right)$ while the sample is rotated step scanned with a total rotational angle of $360^{\circ}$ in the cone-beam geometry $\left(140^{\circ}\right)$ of the tomograph. Each saved projection is an average of 12 frames captured at 3.5 frames per second. After each complete scan of 1440 radiographs (total $8.5 \mathrm{Go}$ ) 36 additional projections were recorded (one radiograph every $10^{\circ}$ ) to correct any eventual drift in sample position and X-ray focus point during the scan. For all the results presented there was a very good superimposition of the projections obtained at the initial scanned angles and after check over the rapid $360^{\circ}$ rotation of the sample. The non-uniform illumination intensity was normalized by dividing through reference (sample-out of the beam) images (flat-field correction). From the 1440 projections the $3 \mathrm{D}$ distribution of the $\mathrm{X}$-ray attenuation coefficient was determined from the attenuation in the transmitted beam [31]. Thus, the direct beam images collected during the scan were used to reconstruct the absorption contrast tomogram of the sample by conventional filtered backprojection reconstruction [32] using the XAct software from RXSolutions. Suppression of systematic errors and artifacts in the tomogram slices (such as scatter due to the finite-sized beam, concentric rings caused by defective detector elements (pixels) or inhomogeneity in their transfer response, etc.) was carried out by standard methods [33]. Thus, ring artifacts suppression was obtained using common approaches as summarized briefly: First, the flat-field correction was used to take into account the non-uniformity in the response of the scintillator and CCD detector when no sample is placed in the X-ray beam. Then, polar space based methods were used to decrease the suppression complexity by transforming the rings on the tomogram slice to linear stripes [34]. Finally, smoothing filters were applied to the sinogram image (or reconstructed image) to remove the ring artifacts while preserving all the structure information in the image. Edge artefacts were cropped digitally. All the processes for analysis and visualization of the tomograms were performed using the VGSTUDIO MAX software.

\section{Modelling fracture saturation}

COMSOL Multiphysics ${ }^{\circledR}$ - a general-purpose platform software for modelling engineering applications was used to model edge crack saturation in panel paintings. The 2D model of a cupped panel painting is shown in Fig. 2. It was assumed that initially the painting was uniformly cupped with the paint layer facing outwards and the cupping had a circular shape. The inner radius $r$ of the cupping varied in a range of $0.5-10 \mathrm{~m}$ typical of real panel paintings. The pictorial layer was represented by a layer of gesso, the component which is most brittle and vulnerable to cracking.

The thickness of the gesso layer $t$-and also the height of pre-existing fractures-was $1 \mathrm{~mm}$. The thickness of wooden panel $T$ was changed in the range between 5 and $40 \mathrm{~mm}$ typical of historical panels. The out of plane direction corresponded to the longitudinal, dimensionally stable direction of wood, therefore, the condition of plane strain was adopted (strain $\varepsilon_{z}=0$ ), evidenced by earlier experimental data [35]. The width of the modelled part $W$ varied depending on a spacing between cracks $S$ at the gesso surface so that the distance from each boundary to the nearest crack was three times of $S$. Hence, the total width of the modelled part was $9 \mathrm{~S}$ as crack thickness was negligible. Surface or sub-surface flaws were positioned in the centre of a gesso island which is the privileged location for the new crack formation [21]. The flaw was infinitesimally narrow, and its length $h$ was varied between 0.01 and $0.4 \mathrm{~mm}$. The surface flaw started from the surface and the flaw tip was located at depth corresponding to crack length $h$. The centre of the sub-surface flaw was positioned at depth $H$, which was changed to cover the entire gesso thickness, but the flaw did not reach the gesso-wood interface or the gesso surface. The maximum size of the flaw was estimated from the microtomography measurements described above.

Calculations were preformed assuming a fully elastic behaviour of all materials. Elasticity moduli determined in this study for selected gesso compositions and RH levels were used. The Poisson's ratio of the gesso layer $v_{g}$ determined experimentally, was 0.2 [5]. Gesso moisture expansion coefficient was assumed to be 0 , which seemed a fair assumption as moisture expansion coefficient of gesso is very small $[5,13]$. The material properties of the wooden support corresponded to lime wood (Tilia sp.) at $\mathrm{RH}=50 \%$ [25]. Namely, the moisture related expansion of lime wood was approximated by a linear dependence on $\mathrm{RH}$ and the moisture expansion coefficients determined for a 5-85\% RH range were $\alpha_{R}=3^{*} 10^{-4}$ and $\alpha_{T}=4.7^{*} 10^{-4}[1 / \% \mathrm{RH}]$ in the radial and tangential directions, respectively [1]. The elasticity moduli, determined experimentally, were $E_{R}=875 \mathrm{MPa}$ and $E_{T}=480 \mathrm{MPa}$ in the radial and tangential directions, and $G=226 \mathrm{MPa}$. 


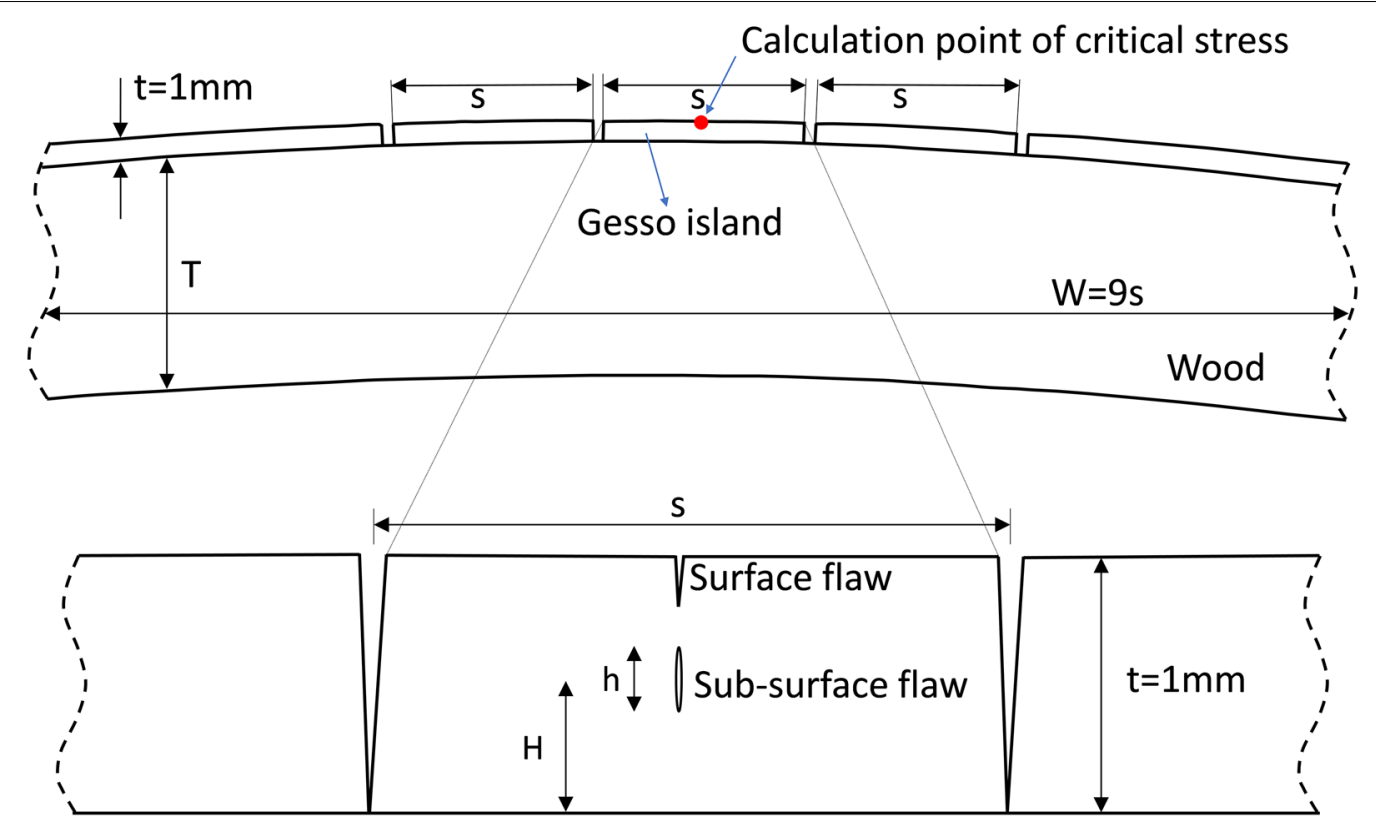

Fig. 2 Model of a panel painting. Cupping of the wooden substrate, cracks in the gesso layer and locations of surface and subsurface flaws are indicated

The Poisson's ratio $v_{T R}$ corresponding to a contraction in the radial direction when tension is applied along the tangential direction was assumed at $0.346[36]$ and $v_{R T}$ was 0.631 .

The lower corners of the painting were fixed in the $y$-direction but were free to move in the $x$-direction. Such configuration of the boundary conditions enabled cupping of the painting during expansion of the wooden support in the $\mathrm{x}$-direction on an increase in $\mathrm{RH}$. In order to reduce computational load, a symmetry condition versus the Y-axis was applied in the centre of the model. A self-adaptive finite element mesh was used during simulations with total number of computational nodes not smaller than 25,000, with a finer mesh in the central and neighbouring gesso islands.

\section{Results and discussion}

\section{Stiffness and mode I fracture toughness $G_{I C}$ of the gesso}

Stiffness of gesso practically did not depend on the PVC ratio within experimental uncertainty. Elasticity modulus varied significantly with RH and was 10.2, 7, 3.8 and $0.4 \mathrm{GPa}$ at $30,50,75$ and $90 \% \mathrm{RH}$, respectively, which agrees with the tendencies established in earlier studies $[5,13]$. For RH lower than $90 \%$, uncertainty was around $1 \mathrm{GPa}$ and for $90 \%$ was $0.4 \mathrm{GPa}$. The material's glass transition, that is to say from the brittle to ductile (gel-like) state, is observed at approximately $75 \%$ and coincides with significant increase of moisture adsorption by animal glue [5]. Above this RH level, gesso becomes easily deformable and strain at break increases at least by an order of magnitude when compared to the values at $\mathrm{RH}$ lower than $75 \%$. In its brittle state below the glass transition, gesso is much stiffer than wood substrates. By way of example, the elasticity moduli of lime wood considered as the wood substrate in this study are 875 and $480 \mathrm{MPa}$ in the radial and tangential directions, respectively [25].

Fracture toughness $G_{I C}$ determined for four types of gessoes of varying PVC and equilibrated at four different $\mathrm{RH}$ is shown in Fig. 3. The figure demonstrates that $G_{I C}$ is roughly constant for PVC lower than $91.3 \%$ within experimental uncertainty and starts to decrease above this value. Above $95 \%$, there is practically no bonding in the gesso. By fitting the two-segment linear function to all experimental data, it was determined that $G_{I C}=-0.8$ $( \pm 3) * \mathrm{PVC}+178( \pm 278) \mathrm{N} / \mathrm{m}$ for $\mathrm{PVC}<91.3 \%$, and $G_{I C}=$ $-23.8( \pm 2.7) * \mathrm{PVC}+2279( \pm 448) \mathrm{N} / \mathrm{m}$ for $\mathrm{PVC}>91.3 \%$. The two-segment linear dependence on PVC was also observed for stiffness and strength of gesso by Michalski [27] who determined that the bonding in gesso drops to zero for PVC higher than $94 \%$. Michalski interpreted the two-segment linear behaviour in terms of interparticle bonding area which increases steeply with even slight decrease in PVC for gessoes with a low amount of glue (high PVC) as any additional amount of glue bridges particles effectively. When most facets of polyhedral particles are bridged, adding more glue contributes to further bridging only slowly. Therefore, $G_{I C}$ levels off for higher amounts of the glue. However, further increase of the 


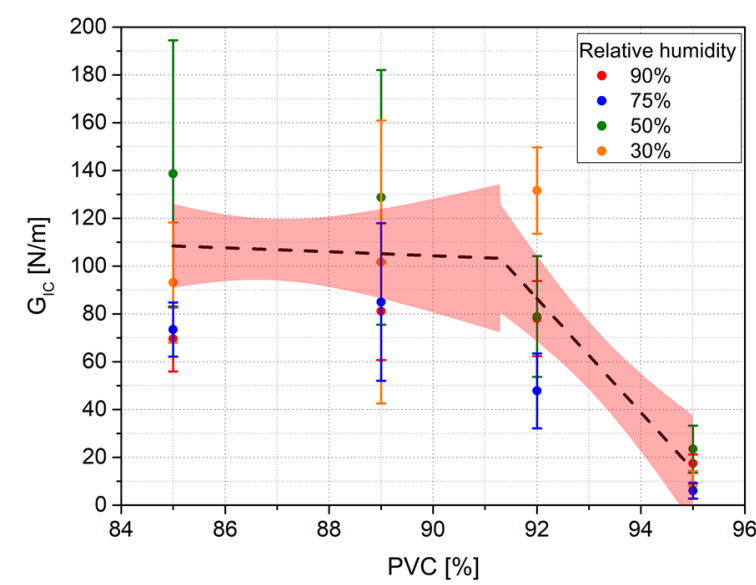

Fig. 3 Mode I fracture toughness $G_{I C}$ for various PVC and RH values. The dashed line represents the two-segment linear regression and the reddish area indicates $95 \%$ confidence bands glue amount results in a decrease of the fracture toughness to the value characteristic of the pure glue as crack propagation is arrested better in the gesso than in the glue. In the light of presented results, gessoes of PVC higher than $94 \%$ are very week.

The fracture usually propagated both cohesively through the gesso and adhesively (interfacially) between the gesso and the wood. There was no correlation between the $G_{I C}$ value of an individual specimen and the dominating fracture propagation mode, adhesive or cohesive, indicating that $G_{I C}$ for both modes were similar. Similar behaviour was observed for a foundation layer used in wooden lacquer objects and for several adhesives used in their conservation [37].

A significant relative uncertainty of $G_{I C}$, ranging between $14 \%$ and $60 \%$ for usable gessoes of PVC of $92 \%$ and $89 \%$, respectively, for the measurements at $30 \% \mathrm{RH}$, indicates large variability in the inhomogeneous samples across each individual set. Within the uncertainty, $G_{I C}$ did not depend consistently on $\mathrm{RH}$ at which the sample was equilibrated for all PVC values but further research clarifying the issue is needed. This is an interesting result as gesso significantly softens at high $\mathrm{RH}$ as demonstrated above. Lack of the $G_{I C}$ dependence on $\mathrm{RH}$ and thus on the moisture content can be interpreted by compensation of a decrease in material stiffness by an increase in strain at break, so that the energy required to break apart glue molecules bonding particles remains invariant.

\section{Edge crack saturation}

Finite element analysis was used to model the stress distribution at the surface of a flaw-free cracked gesso layer. The thickness of the gesso layer-and also the height of

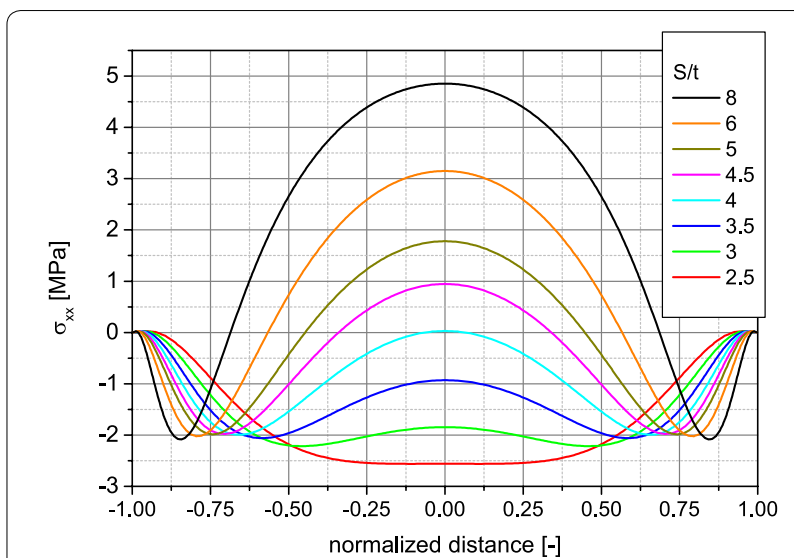

Fig. 4 Distributions of horizontal stress $\sigma_{x x}$ in the flaw-free islands of gesso. The distributions are plotted as a function of a fraction of normalized distance between cracks for various $S / t$ ratios. Gesso elasticity modulus was $E_{\text {gesso }}=1.2 \mathrm{GPa}$. Wooden support was $10 \mathrm{~mm}$ thick and initially cupped with $r=5 \mathrm{~m}$

pre-existing fractures-was $1 \mathrm{~mm}$ following the outcome of a systematic study of about 50 Italian panel paintings in which the gesso thickness ranged between 0.3 and $1.9 \mathrm{~mm}$ but concentrated in a domain slightly below $1 \mathrm{~mm}$ [38]. Exemplary results are shown in Fig. 4 for a panel painting with an initial permanent deformationcupping, as in historical objects. As stress in the x-direction reaches its maximum in the centre of each 'island' for large ratios of spacing between cracks $S$ to gesso layer thickness $t$, the islands tend to form cracks in the middle. For decreasing $S / t$, the stress drops to zero and becomes negative, thus no new crack will ever form. The critical crack separation $(S / t)_{c r}$ is defined as the $S / t$ ratio for which stress $\sigma_{x x}$ in the midpoint drops to zero. The results also showed that the distribution of stress-horizontal $\sigma_{x x}$, vertical $\sigma_{y y}$ and shear $\sigma_{x y}$-practically did not depend on radius of the initial circular cupping-either at the gesso surface or in the bulk-for realistic values of $r$ ranging from 0.5 to $10 \mathrm{~m}$. Radius of $0.5 \mathrm{~m}$ corresponds to a painting which is very significantly cupped whereas radius of $10 \mathrm{~m}$ to a painting of negligible cupping. This can be explained by relatively slight deformation of the panel painting compared to its thickness.

Figure 5 shows how the tendency of a painting to cupping induced by swelling of the wooden support on an increase in ambient $\mathrm{RH}$, which modifies the initial deformation of the painting affects the stress distribution in the gesso layer, particularly on the surface (Fig. 5). The outcome of cupping is a decrease in tensile stresses in the gesso layer due to a restraint on wood swelling exerted by the gesso layer which makes the gesso less vulnerable to cracking. The effect is most pronounced for relatively thin wooden supports and stiff gessoes. The modelling 


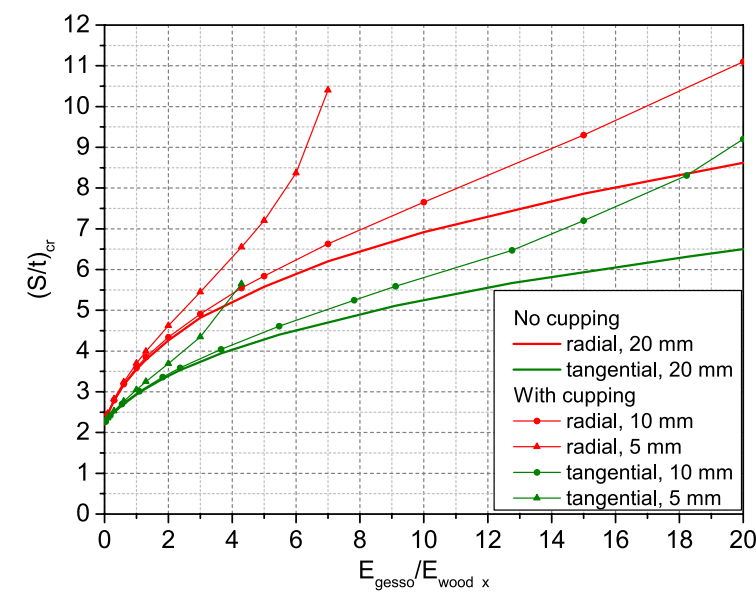

Fig. 5 Critical crack separation distance $(S / t)_{c r}$ for cupped panel paintings established for various thicknesses $(5,10$ or $20 \mathrm{~mm}$ ) and orientations of the wooden support in which hygric strain of wood in the $x$-direction was 0.01 . Values of $(S / t)_{c r}$ obtained for flat panel paintings uniaxially stretched are shown for comparison [22]. The effect of cupping for panels $20 \mathrm{~mm}$ thick was very small and the plots are not presented

demonstrated that for wooden supports $5 \mathrm{~mm}$ thick and the ratio of elasticity moduli $E_{\text {gesso }} / E_{\text {wood_x }}$ less than 4.2 or 7 for the tangential or radial directions, respectively, expanding wooden supports induced compression not tension in most of the gesso layer. As a result, the condition defining $(S / t)_{c r}$ could not be fulfilled and edge cracks could not grow.

\section{Simulation of infilling process}

J-integral-a parameter commonly used in fracture mechanics [39] - was calculated to evaluate the local elastic-plastic fields in the vicinity of flaw tips. It was shown by several authors $[40,41]$ that the parameter can be calculated for any crack configuration and geometry of loading and corresponds to the energy release rate. It was assumed that the analysed system represented the plane strain case as wood is dimensionally stable in the $\mathrm{z}$-direction. In such case, with the propagation of flaw in the $y$-direction, the $J$ integral expression in Cartesian coordinates takes form:

$$
J=\int_{\Gamma}\left(W d x-T \frac{\delta u}{\delta y} d s\right)
$$

where $\Gamma$ is a contour surrounding the notch tip and the integral is evaluated in a counter clockwise sense, $W$ is the strain-energy density, $T$ is the traction vector defined according to the outward normal along $\Gamma, u$ is the displacement vector, and $d s$ is an infinitesimal arc length along $\Gamma$. The selection of the clockwise direction followed the convention that the J-integral has a positive value.

In the modelling, the worst-case scenario for the infilling process was evaluated involving the flat geometry of a panel painting with boundary conditions from [21] and panel thickness of $40 \mathrm{~mm}$ assumed to be the largest thickness encountered in historical panel paintings. The geometry engendered the largest stresses in the gesso layer due to the dominating effect of a thick panel on the painting response and resulting negligible moisture induced cupping which, therefore, was disregarded. The calculations were performed for the applied strain $\varepsilon_{x}=0.01$, the tangential direction, and stiffness of gesso $E_{\text {gesso }}$ varying between 1 and $10 \mathrm{GPa}$, representing change of the parameter within an $\mathrm{RH}$ range between 30 and $85 \%$ typically encountered in museums and historical buildings. Length of surface and subsurface flaws was varied between 0.01 and $0.4 \mathrm{~mm}$. Further, the position of the sub-surface flaws $H$ was changed to cover the entire gesso thickness with step of $0.05 \mathrm{~mm}$, and flaw tip orientation between upper and lower. Complete set of relationships between the energy release rate calculated as J-integral and $S / t$ ratios for various combinations of the gesso stiffness and flaw geometries are shown in Figs. 6 and 7.

As expected, $G_{I}$ was found to increase with length of the flaw, therefore, the largest flaws in the gesso layer determine the susceptibility of the material to infill crack development. For large $S / t$ ratios, maximum $G_{I}$ is reached by the upper tip of a flaw positioned closer to the surface, but the situation reverses for smaller $S / t$ ratios where maximum $G_{I}$ is identified for the lower tip of a flaw positioned closer to the gesso-wood interface. X-ray computer microtomography was used to determine dimensions of flaws in a specimen of a typical historical gesso. Air bubbles and voids predominate as structural flaws and they act as initiation sites for cracks that propagate and reach the wood interface (Fig. 8). The maximum bubble diameter observed using the microtomography was $0.2 \mathrm{~mm}$. Conspicuously, the same value of the maximum flaw dimension was obtained from the calculations of $G_{I}$ for newly prepared (not cracked) gesso specimens which fail in tensile testing at the strain of approximately 0.002 . The elasticity modulus of the gesso is between 7 and $3.8 \mathrm{GPa}$ as $\mathrm{RH}$ increases from 50 to $70 \%$. Assuming that the failure (cracking) initiated at the largest structural flaws, $G_{I}$ reached the critical value of $100 \mathrm{~N} / \mathrm{m}-$ typical of usable gessoes (Fig. 2)-at applied strain $\varepsilon_{x}$ of 0.002 for the flaw dimension of $0.2 \mathrm{~mm}$ on average (Fig. 9).

Figure 10 shows the energy release rate calculated as J-integral for varying gesso stiffness, two surface or subsurface locations of flaws, and various $S / t$ ratios. The flaw 

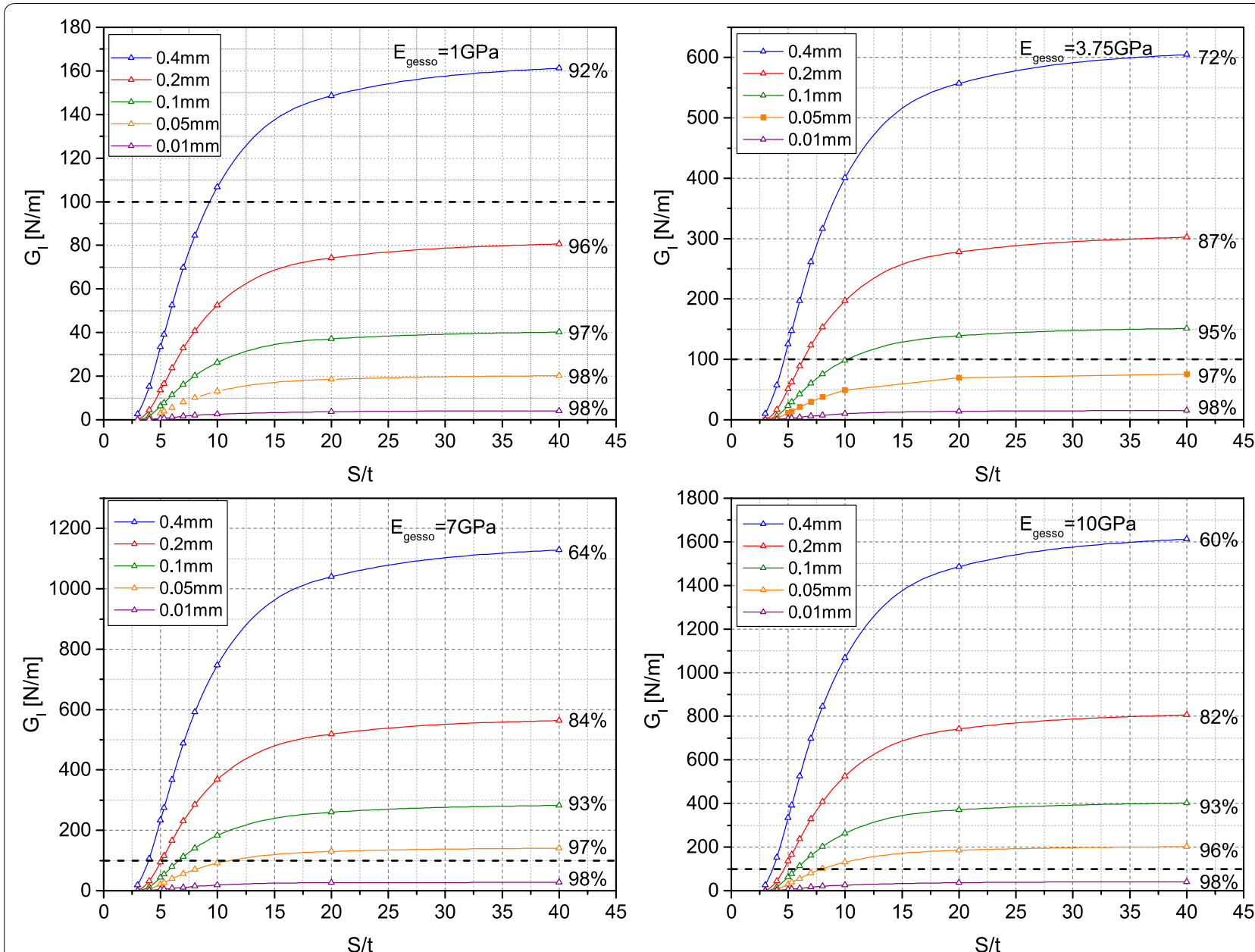

Fig. 6 Energy release rate $G$, for a flaw located at the gesso surface. The parameter was determined for varying gesso stiffness and length $h$ of a flaw $(0.01-0.4 \mathrm{~mm})$. A percentage of the final $G$, for the case of the gesso layer with no cracks is given for $S / t$ of 40 . The dashed line indicates the average value of $G_{I C}$ determined for gessoes of PVC 92,89 and $85 \%$. The applied strain $\varepsilon_{x}$ was 0.01

length assumed was $0.2 \mathrm{~mm}$, typical of newly prepared and historical gessoes as demonstrated above. When the surface cracks develop (solid lines), $G_{I}$ decreases slowly with a decrease in $S / t$ until a value of $10-15$ is reached. Below this value, $G_{I}$ drops rapidly reaching 0 for $S / t$ of approximately 3 , independently of gesso stiffness. One can interpret the obtained result assuming that strain $\varepsilon_{x}=0.01$ induces propagation of the flaw if $G_{I}$ is higher than $G_{I C}$ of approximately $100 \mathrm{~N} / \mathrm{m}$. When the network of cracks concentrates, the $S / t$ ratio decreases reducing $G_{I}$. Below a certain value of $S / t$, a surface flaw cannot grow. If the $S / t$ ratio is smaller than 3 , surface flaws do not develop, irrespectively of gesso stiffness and applied strain $\varepsilon_{x}$.

The relationship between $G_{I}$ and the $S / t$ ratio for the sub-surface flaws is somewhat more complex. When cracks develop, $G_{I}$ decreases with a decrease in $S / t$ ratio until $5,7.5,10$ or 12.5 is reached for gesso stiffness of 1 ,
$3.75,7,10 \mathrm{GPa}$, respectively. Below the above critical $S / t$ values, $G_{I}$ levels off before decreasing slowly. Characteristically, at the $S / t$ ratio of around 4-5, $G_{I}$ of sub-surface flaws overrides $G_{I}$ of surface cracks. Therefore, for small $S / t$ ratios, there is a continuous change in the mechanism of crack formation from downward propagation of surface flaws to growth of sub-surface flaws located close to the gesso-wood interface towards the surface.

\section{Vulnerability of gessoes with craquelures to $\mathrm{RH}$ variations}

Figure 11 shows the calculated distance between cracks for a representative flaw length $h=0.2 \mathrm{~mm}$ as a function of applied tensile strain $\varepsilon_{x}$ varying between 0.002 and 0.04 . The second bottom axis in the diagram indicates RH levels which induced the $\varepsilon_{x}$ strain in the gesso layer through moisture related swelling of lime wood in the tangential direction [25] assuming that at 50\% $\mathrm{RH}$ the strain in the material is zero. The RH scale allows the 

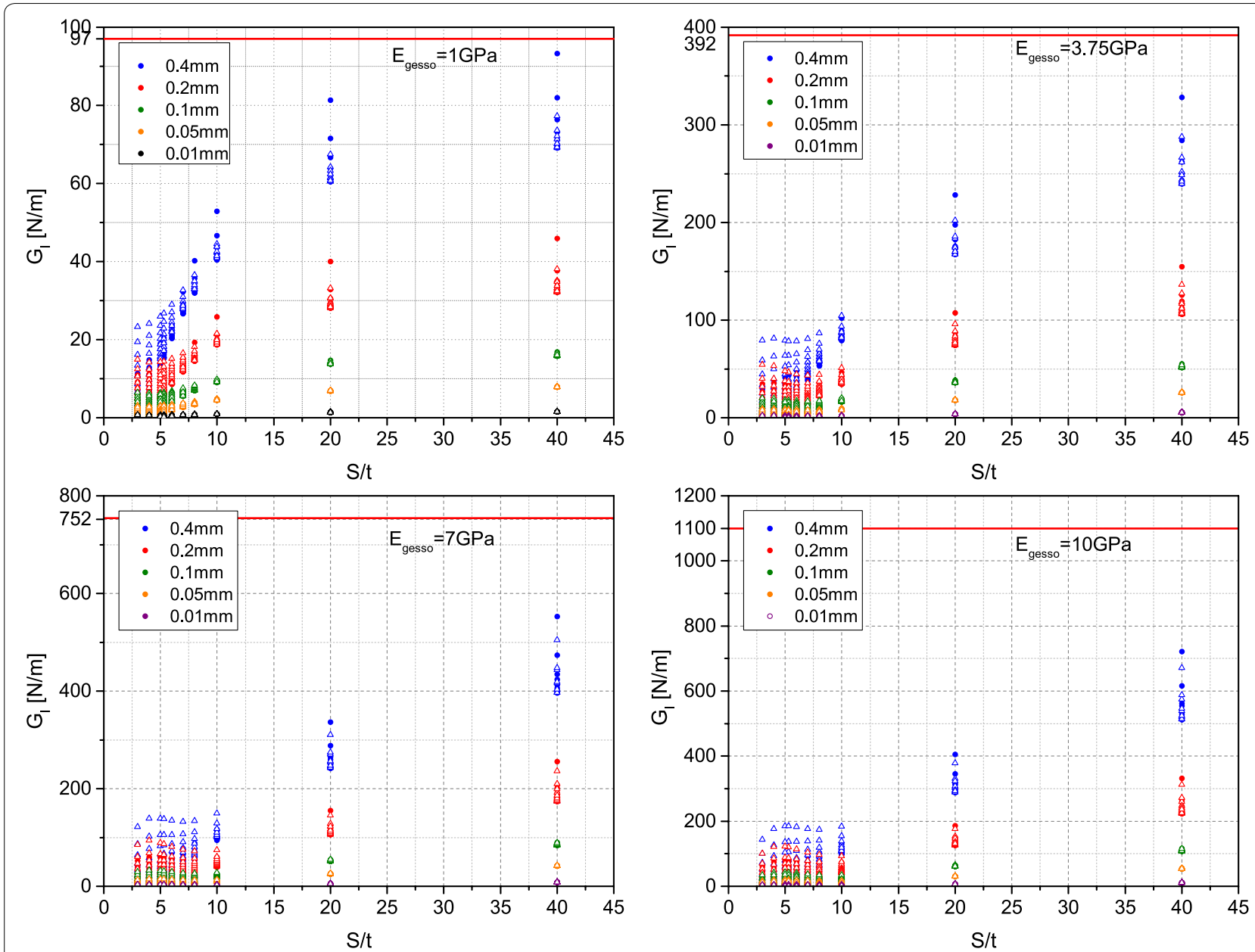

Fig. 7 Energy release rate $G$, for a sub-surface flaw. The parameter was determined for varying gesso stiffness, flaw length $h(0.01-0.4 \mathrm{~mm})$ and position $H$, and upper (solid circles) and lower (open triangles) tips of sub-surface flaws. The highest value of $G$, for a flaw of length $h=0.4 \mathrm{~mm}$ in the case of the gesso layer with no cracks ( $S / t$ is infinite) is marked on the $Y$ scale. The applied strain $\varepsilon_{x}$ was 0.01

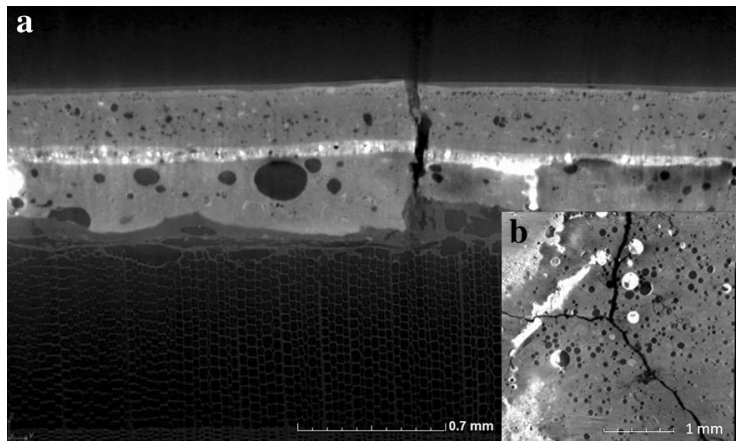

Fig. 8 X-ray microtomographs of a layer of historical paint layer. a Cross-section perpendicular to the surface. The gesso is visible as third layer from the bottom after wood and sizing. $\mathbf{b}$ Cross-section parallel to the surface. The tomograms were recorded with a voxel size of $3 \mu \mathrm{m}$. For presentation, the $X$-ray absorbing material is represented on a grey scale and the air in black

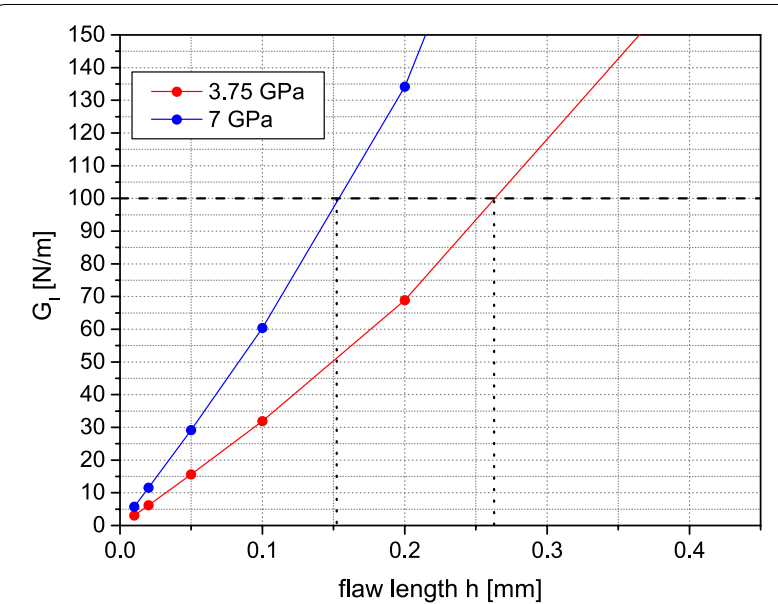

Fig. 9 Energy release rate $G$, as a function of flaw length. The parameter was determined for gessoes of stiffness 3.75 and $7 \mathrm{GPa}$ and applied strain $\varepsilon_{x}$ of 0.002 as a function of flaw length 


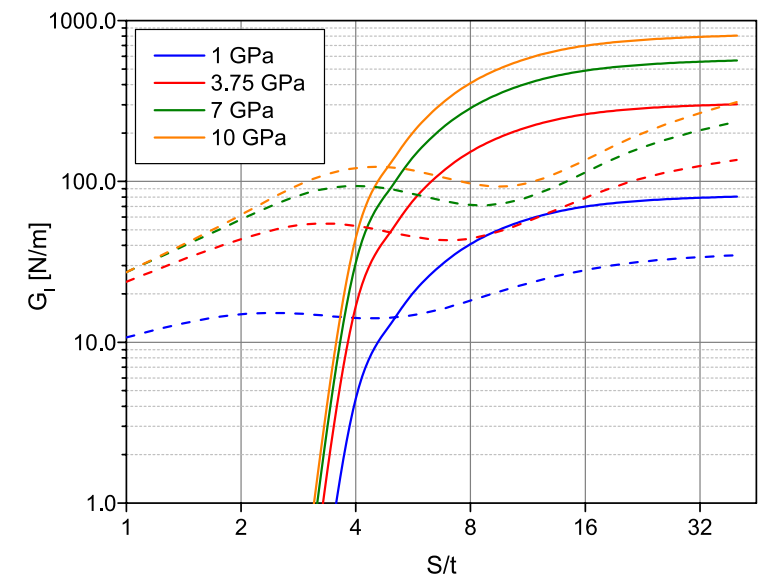

Fig. $10 G$, for varying gesso stiffness and flaws. Surface (solid line) and sub-surface (dashed line) flaws were of length $h=0.2 \mathrm{~mm}$. The subsurface flaws were located at $H=0.85 \mathrm{~mm}$. The applied strain $\varepsilon_{x}$ was 0.01

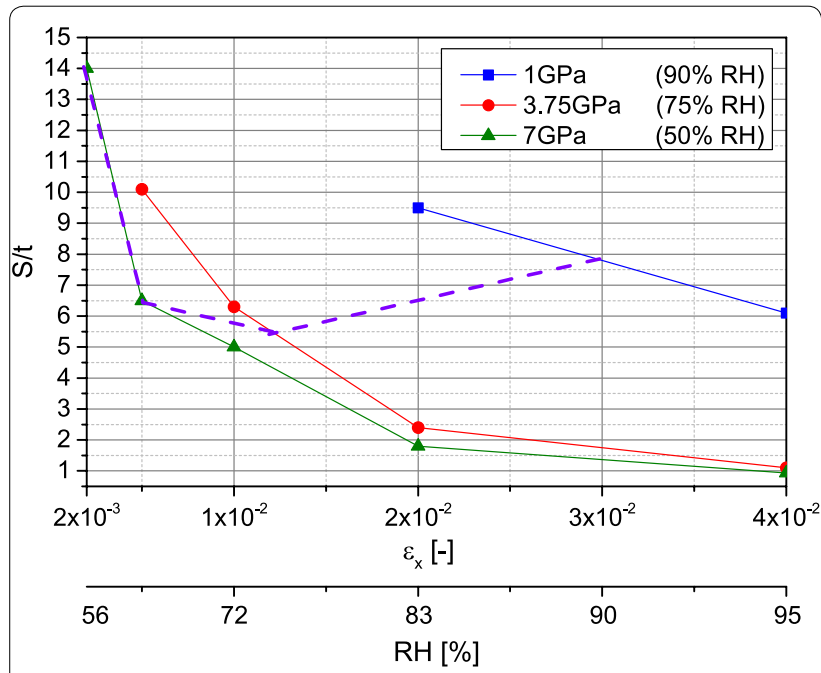

Fig. 11 Distance between cracks in the gesso. The normalised distance between the cracks in the gesso layer $S / t$ for length of a surface flaw $h=0.2 \mathrm{~mm}$ is plotted as a function of applied strain $\varepsilon_{x}$. The second bottom axis shows change in $\mathrm{RH}$ corresponding to hygric strain in the tangential direction in lime wood

$\varepsilon_{x}$ strain experienced by the gesso layer to be correlated with its stiffness decreasing when $\mathrm{RH}$ reaches and then exceeds $75 \%$. Change in the saturation distance between cracks $(S / t)_{\text {sat }}$ with increasing RH is marked in Fig. 9 with the dashed line. When RH increases above $50 \%$, the saturation distance decreases very rapidly even if an increase in strain is minute. For strains larger than 0.005, concentration of cracks slows down until RH attains $75 \%$. At this $\mathrm{RH}$ level, gesso starts to soften which causes a drop in $G_{I}$ and an increase in $(S / t)_{\text {sat }}$ so that no more cracks can be formed. In consequence, the lowest possible $S / t$ ratio is 5 . By way of example, it was estimated that thickness of the pictorial layer in Memling's painting shown in Fig. 1, dominated by the gesso, is approximately $0.5 \mathrm{~mm}$. The average distance between cracks is ca. $3 \mathrm{~mm}$, resulting in S/t ratio around 6, which is close to the lowest possible $S / t$ ratio of 5 .

To summarize, minimal $(S / t)_{\text {sat }}$ is reached in paintings, even with surface or subsurface flaws at which cracks initiate, owing to two effects. One is a decrease in tensile stresses in the fracturing material if the distance between cracks decreases and the second is softening of the gesso layer with increasing RH. Both processes lead to a decrease in stored elastic energy in the system. If the stored energy drops below values corresponding to the fracture toughness, cracks cannot grow.

As demonstrated earlier in this paper, the potential for crack development in the gesso layer depends significantly on its fracture toughness, which can be significantly lower than $100 \mathrm{~N} / \mathrm{m}$ for gessoes of PVC higher than 92\% (Fig. 3), and size of flaws larger than $0.2 \mathrm{~mm}$ (Figs. 6, 7, 9) which depends on amount of water used during gesso preparation. Generally, these parameters cannot be determined for historical paint layers mainly due to limited access to macroscopic samples. However, we have carried out analysis of $G_{I}$ normalized to the same parameter for the gesso layer without cracks for a broad range of elasticity moduli and flaw lengths. The normalized $G_{I}$ reaches maximum value of 1 for large $S / t$ ratios and drops below 0.2 for $S / t$ ratios smaller than 5 (Fig. 12). This result can be interpreted in the following way. Whatever the strain causing first crack initiation (infinite $S / t$ ), strain at least five times larger would be

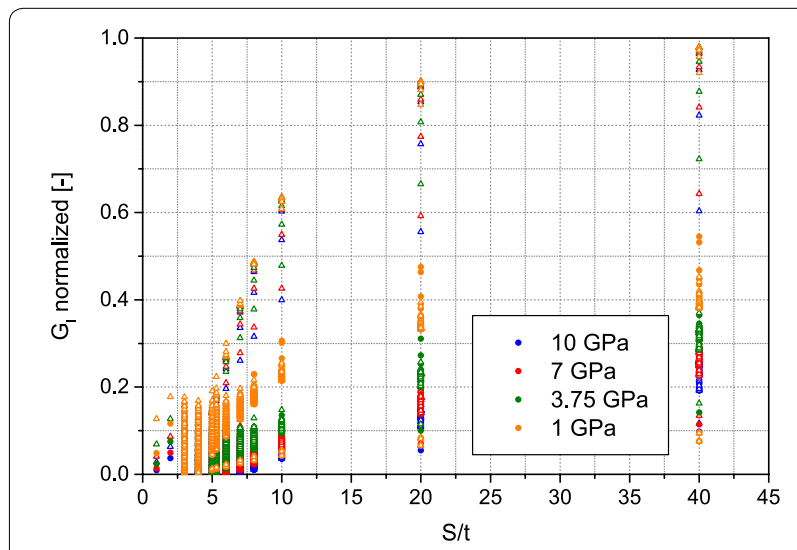

Fig. 12 Energy release rates $G$, normalized to the same parameter for the gesso with no cracks. The parameter was determined for several elasticity moduli and the same flaw lengths as in Figs. 6 and 7. Solid circles and opened triangles indicate normalized $G$, for upper and lower flaw tips, respectively 
necessary to cause any flaw propagation if $S / t$ is smaller than 5. Approximately, this five-time factor applies also to $\mathrm{RH}$ changes inducing the above strains. The above conclusions are valid for paintings with "opened" cracks. If the cracks are filled in during conservation treatment or varnishing, the vulnerability of a painting to environmental variations increases. Impact of various conservation materials on crack saturation is an interesting and important topic meriting further study.

\section{Conclusions}

The most general conclusion from this study is that historical panel paintings with developed craquelure patterns are significantly less vulnerable to climate variations than indicated by earlier studies of fracture risk for pictorial layers based on laboratory testing of undamaged materials. Fracture toughness $G_{I C}$ was used as a 'failure criterion, that is to say, allowable tensile strains in the pictorial layer should not induce energy release rate $G_{I}$ exceeding $G_{I C}$ so that new cracks from flaws in the gesso structure considered as the crack initiation sites do not propagate. Fracture toughness was proved to have a constant value of $100 \mathrm{~N} / \mathrm{m}$ across a range of compositions of usable gessoes and for various relative humidities. Comparison of energy release rate calculated for the model of panel paintings using finite element method with the $G_{I C}$, allowed the crack stability to be analysed for various combinations of the gesso stiffness and flaw geometries. Flat geometry of a panel painting and panel thickness of $40 \mathrm{~mm}$ was identified to represent the worst-case as stresses engendered in the gesso layer are the largest due to the dominating effect of a thick panel on the painting response. For this case, the fracture saturation occurs when the normalized distance between cracks $S / t$ is larger than 5 , even if flaws in the gesso layer are present.

Although, computerized microtomography was used in this study to determine maximum size of the flaws in the gesso, the technique can deliver statistical information on grain size distribution in historic materials, structure of paint layers, and craquelure patterns. All this information is of critical importance for understanding how various craquelure patterns were formed. However, computerized microtomography is a micro-destructive technique as samples of several $\mathrm{mm}$ in size need to be collected from an object investigated. This aspect may somewhat limit feasible diagnostic studies of historical panel paintings with the use of the technique.

The study opens path to re-defining the current 'baseline' for the environmental standards for safe display of painted wood which allow moderate variations within the range $50 \pm 10 \% \mathrm{RH}$. This safe range was derived using the strain at break for newly prepared gesso with no cracks as the failure criterion. Refining the failure criteria through the experimental work and modelling allowed the physical reality of historical panel paintings to be addressed better and departures from the long-term, average mid$\mathrm{RH}$ level to higher $\mathrm{RH}$ values to be characterized as involving no risk of further cracking. The finding offers a potential explanation as to why historical panel paintings with developed craquelure patterns remain stable in environments far from the 'ideal' museum conditions. The study will hopefully contribute to development and acceptance of more rational, moderate-cost climate control strategies in historic buildings and museums, often with limited potential for tighter climate control unless serious alterations to these structures and huge energy costs are accepted.

\section{Supplementary information}

Supplementary information accompanies this paper at https://doi. org/10.1186/s40494-020-0352-0.

Additional file 1. Preparing and determining mechanical and moisture related properties of gessoes.

\section{Abbreviations \\ DCB: Double cantilever beam; PVC: Pigment volume concentration; RH: Rela- tive humidity.}

\section{Acknowledgements}

D. Favier of the Institut Charles Sadron, Université de Strasbourg is gratefully acknowledged for his involvement in the tomography experiments.

\section{Authors' contributions}

$Ł B$ and KGA fabricated the samples, performed the measurements and modelling. PK carried out $\mu X C T$ measurements. $Ł B$ conceived the experiment and modelling, analysed and interpreted the data, and wrote first version of the manuscript. All authors read and approved the final manuscript.

\section{Funding}

This work was financed by Yale University, The Polish National Agency for Academic Exchange [Grant PPN/PPO/2018/1/00004/U/00001], and the statutory research fund of the Jerzy Haber Institute of Catalysis and Surface Chemistry Polish Academy of Sciences.

\section{Availability of data and materials}

All data needed to evaluate the conclusions in the paper are present in the paper and/or Additional file. Additional data related to this paper may be requested from the corresponding author.

\section{Competing interests}

The authors declare that they have no competing interests.

\section{Author details}

${ }^{1}$ Institute for the Preservation of Cultural Heritage, Yale University, New Haven, CT, USA. ${ }^{2}$ Jerzy Haber Institute of Catalysis and Surface Chemistry Polish Academy of Sciences, 30-239 Kraków, Poland. ${ }^{3}$ Institut Charles Sadron, Université de Strasbourg, CNRS-UPR22, 67034 Strasbourg, France.

Received: 20 November 2019 Accepted: 17 January 2020

Published online: 20 February 2020 


\section{References}

1. Bratasz $Ł$, Kozłowski R, Kozłowska A, Rachwał B. Sorption of moisture and dimensional change of wood species used in historic objects. In: Gril J, editor. Wood Science for Conservation of Cultural Heritage. In: Proceedings of the international conference held by COST action IE0601, Braga, Portugal, 5 to 7 November 2008. Florence: Firenze University Press; 2010 p. 11-6.

2. Mecklenburg MF, Tumosa CS, Erhardt D. Structural response of painted wood surfaces to changes in ambient relative humidity. In: Dorge $\mathrm{V}$, Howlett FC, editors. Painted wood: history and conservation. Los Angeles: The Getty Conservation Institute; 1998. p. 464-83.

3. Thomson G. The museum environment. 2nd ed. London: ButterworthsHeinemann; 1986

4. Fuster Lopez L. Estudio de la idondeidad de las masillas de relleno en el tratamiento de lagunas en pintura sobre lienzo. Thesis. Universidad Politecnica de Valencia; 2005.

5. Rachwał B, Bratasz Ł, Krzemień L, Łukomski M, Kozłowski R. Fatigue damage of the gesso layer in panel paintings subjected to changing climate conditions. Strain. 2012;48:474-81.

6. Erhardt D, Mecklenburg MF. Relative humidity re-examined. In: Roy A, Smith P, editors. Preventive conservation practice, theory and research. London: International Institute of Conservation; 1994. p. 32-8.

7. Museums, Galleries, Archives and Libraries. ASHRAE Handbook, Chap. 21. Atlanta: American Society of Heating and Air-Conditioning Engineers: 2007.

8. Bickersteth J. IIC and ICOM-CC Declaration on environmental guidelines Stud Conserv. 2016:61(1):12-7.

9. Ascione F, Bellia L, Capozzoli A, Minichiello F. Energy saving strategies in air-conditioning for museums. Appl Therm Eng. 2009:29:676-86.

10. Smithsonian's Museum Conservation Institute. Culmination of 20 years of green, energy savings research. Washington: Smithsonian's Museum Conservation Institute; 2015. https://www.si.edu/mci/english/research/ consulting/MuseumEnvironment.html, Accessed 19 Nov 2019.

11. Kramer R. Clever climate control for culture-energy efficient indoor climate control strategies for museums respecting collection preservation and thermal comfort of visitors. Thesis. Eindhoven University of Technology; 2017.

12. Bucklow SL. The description of craquelure patterns. Stud Conserv. 1997;42:3129-40

13. Krzemień $L$, Łukomski M, Bratasz Ł, Kozłowski R, Mecklenburg MF. Mechanism of craquelure pattern formation on panel paintings. Stud Conserv. 2016:61:324-30.

14. Wu H, Pollard DD. An experimental study of the relationship between joint spacing and layer thickness. J Struct Geol. 1995:17:887-905.

15. Bucklow SL. Consensus in the classification of craquelure. Hamilton Kerr Institute Bulletin 3. Cambridge: Fitzwilliam Museum; 2000. p. 61-73.

16. Shevchuk VA, Silberschmidt V. Semi-analytical analysis of thermally induced damage in thin ceramic coatings. Int J Solids Struct. 2005:42:4738-57

17. Hutchinson JW, Suo Z. Mixed mode cracking in layered materials. Adv Appl Mech. 1992;29:63-191.

18. Yin HM. Fracture saturation and critical thickness in layered materials. Int J Solids Struct. 2010:47:1007-15.

19. MaX, Lowensohn J, Burton JC. Universal scaling of polygonal desiccation crack patterns. Phys Rev E. 2019:99:012802.

20. Giorgiutti-Dauphiné F, Pauchard L. Painting cracks: a way to investigate the pictorial matter. J Appl Phys. 2016;120:065107.

21. Bratasz $Ł$, Vaziri Sereshk MR. Crack saturation as a mechanism of acclimatization of panel paintings to unstable environments. Stud Conserv. 2018:63(1):22-7.
22. Narr W, Suppe J. Joint spacing in sedimentary rocks. J Struct Geol. 1991;13:1037-48.

23. Bai T, Pollard DD, Gao H. Spacing of edge fracture in layered materials. Int J Fract. 2000;103:373-95.

24. Allegretti $O$, Raffaelli F. Barrier effect to water vapour of early European painting materials on wood panels. Stud Conserv. 2008;53:187-97.

25. Rachwał B, Bratasz Ł, Łukomski M, Kozłowski R. Response of wood supports in panel paintings subjected to changing climate conditions. Strain. 2012:48:357-444.

26. Vici DP, Mazzanti P, Uzielli L. Mechanical response of wooden boards subjected to humidity step variations: climatic chamber measurements and fitted mathematical models. J Cult Herit. 2006;7:37-48.

27. Michalski S. Crack mechanism in gilding. In: Bigelow D, Come E, Landrey GJ, van Horne C, editors. Gilded wood: conservation and history. Madison: Sound View Press; 1991. p. 171-81.

28. Mecklenburg MF, Tumosa CS. Mechanical behavior of paintings subjected to changes in temperature and relative humidity. In: Mecklenburg MF, editor. Art in transit: studies in the transport of paintings. Washington: National Gallery; 1991. p. 173-217.

29. d'Andrea Cennini C. II libro dell'arte, ca. 1400. 3d ed. New Haven: DV Thompson; 1972

30. ASTM D5528-13. Standard test method for mode I interlaminar fracture toughness of unidirectional fiber-reinforced polymer matrix composites. West Conshohocken: ASTM International; 2013.

31. Baruchel J, Buffière JY, Maire E, Merle P, Peix G. X-ray tomography in material science, general principles. Paris: Hermes Science Publications; 2000.

32. Kak A, Slaney M. Principles of computerized tomographic imaging. New York: IEEE; 1998

33. Kékicheff P, Dabo M, Dalongeville G, Gauthier C, Roland T. Polymeric solid foams: microstructure, topology, and defects determined by high resolution X-ray microtomography. Macromol Symp. 2016;369:56-66.

34. Jha D, Sørensen HO, Dobberschütz S, Feidenhans R, Stipp SLS. Adaptive center determination for effective suppression of ring artifacts in tomography images. Appl Phys Lett. 2014;105:143107.

35. Luimes RA, Suiker ASJ, Jorissen AJM, van Duin PHJC, Schellen HL. Hygromechanical response of oak wood cabinet door panels under relative humidity fluctuations. Herit Sci. 2018;6:72.

36. Forest Products Laboratory. Wood handbook-wood as an engineering material. General Technical Report FPL-GTR-113, chap. 4. Madison: Department of Agriculture, Forest Service, Forest Products Laboratory, p. 3.

37. Schellmann NC, Taylor AC. Establishing the fracture properties of delaminating multi-layered decorative coatings on wood and their changes after consolidation with polymer formulations. J Mater Sci. 2015;50:2666-81.

38. Martin E, Sonoda N, Duval AR. Contribution à l'étude des préparations blanches des tableaux italiens sur bois. Stud Conser. 1992:37:82-92.

39. Rice JR. A path independent integral and the approximate analysis of strain concentration by notches and cracks. J Appl Mech. 1968;35:379-86.

40. Atluri SN, editor. Computational Methods in the Mechanics of Fracture. Amsterdam: North Holland; 1986.

41. Anderson TL. Fracture mechanics fundamentals and application. New York: Taylor and Francis; 2005

\section{Publisher's Note}

Springer Nature remains neutral with regard to jurisdictional claims in published maps and institutional affiliations. 